\title{
Lymph vascular invasion in invasive mammary carcinomas identified by the endothelial lymphatic marker D2-40 is associated with other indicators of poor prognosis
}

\author{
Vanessa FZ Marinho ${ }^{1}$, Konradin Metze ${ }^{2}$, Fernanda SF Sanches ${ }^{1}$, \\ Gislene FS Rocha ${ }^{1}$ and Helenice Gobbi*1
}

Address: ${ }^{1}$ Departamento de Anatomia Patológica, Faculdade de Medicina da Universidade Federal de Minas Gerais (UFMG), Belo Horizonte, Brazil and 2Interdisciplinary group: "Analytical Cellular Pathology", Departamento de Patologia, Universidade Estadual de Campinas (UNICAMP), Campinas, Brazil

Email: Vanessa FZ Marinho - vanessa.zschaber@gmail.com; Konradin Metze - kmetze@pesquisador.cnpq.br;

Fernanda SF Sanches - nandasan@uai.com.br; Gislene FS Rocha - gislene.fatima@gmail.com; Helenice Gobbi* - hgobbi@medicina.ufmg.br

* Corresponding author

Published: 29 February 2008

BMC Cancer 2008, 8:64 doi:10.1 |86/|47|-2407-8-64
Received: 25 September 2007

Accepted: 29 February 2008

This article is available from: http://www.biomedcentral.com/I47I-2407/8/64

(c) 2008 Marinho et al; licensee BioMed Central Ltd.

This is an Open Access article distributed under the terms of the Creative Commons Attribution License (http://creativecommons.org/licenses/by/2.0), which permits unrestricted use, distribution, and reproduction in any medium, provided the original work is properly cited.

\begin{abstract}
Background: Immunohistochemical studies of lymphatic vessels have been limited by a lack of specific markers. Recently, the novel D2-40 antibody, which selectively marks endothelium of lymphatic vessels, was released. The aim of our study is to compare lymphatic and blood vessel invasion detected by hematoxylin and eosin (H\&E) versus that detected by immunohistochemistry, relating them with morphologic and molecular prognostic factors.
\end{abstract}

Methods: We selected I 23 cases of invasive mammary carcinomas stratified into three subgroups according to axillary lymph node status: macrometastases, micrometastases, and lymph node negative. Lymphatic (LVI) and blood (BVI) vessel invasion were evaluated by $\mathrm{H} \& \mathrm{E}$ and immunohistochemistry using the D2-40 and CD3 I antibodies, and related to histologic tumor type and grade, estrogen and progesterone receptors, E-cadherin, Ki67, p53, and Her2/neu expression.

Results: LVI was detected in H\&E-stained sections in $17 / 123$ cases (13.8\%), and in D2-40 sections in $35 / 123$ cases $(28.5 \%)$ (Kappa $=0.433)$. BVI was detected in H\&E-stained sections in $5 / 123$ cases (4.1\%), and in CD3I stained sections in 19/I23 cases (15.4\%) (Kappa $=0.198)$. LVI is positively related to higher histologic grade $(p=0.013)$, higher Ki67 expression $(p=0.00013)$, and to the presence of macrometastases $(p=0.002)$, and inversely related to estrogen $(p=0.0016)$ and progesterone $(p=0.00017)$ receptors expression.

Conclusion: D2-40 is a reliable marker of lymphatic vessels and is a useful tool for lymphatic emboli identification in immunostained sections of breast carcinomas with higher identification rates than H\&E. Lymphatic vessel invasion was related to other features (high combined histologic grade, high Ki67 score, negative hormone receptors expression) associated with worse prognosis, probable reflecting a potential for lymphatic metastatic spread and aggressive behavior. 


\section{Background}

Lymphatic vessels are considered the main route by which tumor cells reach axillary lymph nodes [1-3]. Lymphatic vessel invasion (LVI) is known as an independent predictor of lymph node metastases in breast cancer. The diagnosis of LVI is made based on the presence of tumor emboli within vascular channels lined by a single layer of endothelial cells without red blood cells. Lymphatic vessels are flattened channels or open spaces lined by a single layer of endothelial cells whose lumen are sometimes filled with lymphocytes. However, the identification of LVI is difficult in hematoxylin and eosin (H\&E) stained slides. Retraction artifacts that isolate tumor aggregates due to tissue shrinkage during fixation are sometimes confused with the true tumor emboli in lymphatic vessels $[4,5]$.

Several markers of endothelial cells have been used, including CD31, CD34, and factor VIII-related antigen. However, studies of lymphatic vessels have been limited by lack of specific lymphatic endothelial markers and immunohistochemical identification of lymphatic vessels has been unreliable $[1,6]$. Novel selective markers for lymphatic endothelium have been released, such as LYVE-1, Prox-1, desmoplakin, and podoplanin [7-12]. More recently, the monoclonal antibody D2-40 was shown to selectively detect lymphatic vessels in breast and tonsillar tissue $[13,14]$. D2-40 is an IgG2a monoclonal antibody that was generated against an oncofetal antigen M2A, which is normally expressed in the fetal testis and reexpressed in germ cell neoplasia [15]. It is a novel monoclonal antibody to an $\mathrm{M}_{\mathrm{r}} 40000$ O-linked sialoglycoprotein that reacts with a fixation-resistant epitope on the lymphatic endothelium [16] The D2-40 antibody has been shown to specifically recognize podoplanin, a glomerular podocyte membrane protein $[17,18]$ and has been shown to be a very sensitive and specific marker for lymphatic endothelium in most tissues [19] and especially in breast cancer [20]. D2-40 stains the endothelium of lymphatic vessels, lymphangiomas, Kaposi's sarcoma and Dabska tumor, but does not stain endothelium of blood vessels, hemangiomas, glomus tumors, angiolipomas, pyogenic granulomas, and vascular malformations $[13,14,21,22]$.

The aim of our study is to compare lymphatic vessel invasion (LVI) and blood vessel invasion (BVI) in invasive mammary carcinomas using $\mathrm{H} \& \mathrm{E}$ and immunohistochemical stained sections, relating them to other prognostic factors.

\section{Methods}

We selected 123 patients with invasive mammary carcinomas (IMC), who had been submitted to surgical treatment with axillary lymph node dissection at our hospital between 1990 and 2004. The research was approved by the Ethics Committee of the University. On original histopathologic examination, 41 cases were diagnosed as axillary lymph node negative, 41 cases with micrometastases (defined as neoplastic cell clusters measuring between 0.2 and $2 \mathrm{~mm}$ ), and 41 cases with macrometastases (defined as neoplastic cell clusters larger than $2 \mathrm{~mm}$ ) [23]. No case of isolated tumor cells was included in this study. The mean age of patients, the histologic type and tumor grade of cases of each subgroup were similar. For all cases, the original H\&E-stained sections of primary tumors and axillary lymph nodes were available for histologic review. The paraffin blocks were available for additional sections and immunohistochemical analysis. Special care was taken to include only specimens with sufficient amount of normal tissue surrounding the invasive tumor to evaluate peritumoral LVI and BVI.

Cases were evaluated with regard to age of patients and tumor size using the TNM system [23]. Histologic analysis of primary breast carcinoma features included histologic type, histologic grade, LVI and BVI. The histologic type of primary tumor was classified based on Page et al [24], and the College of American Pathologists recommendations [25], using rigid criteria for classification of special types. Tumor grade was determined using the Nottingham grading system [26]. The diameter of the microscopic field used for mitotic count was $0.44 \mathrm{~mm}$. Primary tumors were analyzed without acknowledgment of the lymph node status.

H\&E-stained sections of primary tumors were reviewed and new histologic consecutive, serial sections were prepared for immunohistochemical analysis. Immunohistochemistry (IHC) was performed on $5 \mu \mathrm{m}$ thickness sections, using monoclonal antibodies (Table 1) and the streptavidin-biotin peroxidase method. Heat-induced epitope retrieval was done with citrate buffer pH6.0 for 25 minutes. Immunohistochemical reactions were developed with diaminobenzidine and sections counterstained with Harrris hematoxylin. All immunostains were manually processed.

IHC using monoclonal anti-cytokeratin antibody (clone AE1/AE3, Dako, USA) was carried out on sections of axillary lymph nodes classified as negative to confirm this status. Cytokeratin reactions were scored as negative or positive. All axillary lymph nodes initially classified as negative continued negative after IHC staining (Table 1 ).

The IHC-stained sections of all primary tumors and axillary lymph nodes were evaluated without knowledge of previous node status. All positive lymph nodes, doubts, and $10 \%$ of negative nodes were re-evaluated by two pathologists (VFZM and HG) using a double-headed 
Table I: Primary antibodies, dilutions, antigen retrieval, and sources of antibodies used in the immunohistochemical study

\begin{tabular}{lllll}
\hline ANTIBODY & CLONE & DILUTION & ANTIGEN RETRIEVAL & SOURCE/COUNTRY \\
\hline D2-40 & D2-40 & $1: 100$ & No & Signet/USA \\
CD3I & JC/70A & $1: 50$ & Yes & Dako/USA \\
P53 & DO7 & $1: 400$ & Yes & Dako/USA \\
ER & $6 F-1 I$ & $1: 100$ & Yes & Novocastra/UK \\
PR & PgR 3I2 & $1: 100$ & Yes & Novocastra/UK \\
Ki67 & MIB-I & $1: 50$ & Yes & Immunotech/France \\
Her2/neu & CBII & $1: 80$ & No & Novocastra/UK \\
E-cadherin & NCH-38 & $1: 50$ & Yes & Dako/USA \\
Cytokeratin & AEI/AE3 & $1: 100$ & Yes & Dako/USA \\
\hline
\end{tabular}

microscope. LVI and/or BVI were assessed by the same pathologists reviewing the $\mathrm{H} \& \mathrm{E}$ and immunohistochemical stained sections. In H\&E-stained sections, LVI and/or BVI were considered evident if at least one tumor cell cluster was clearly visible in the vascular space. In this study, we defined LVI in H\&E-stained sections, as tumor cell nests in spaces and around the clump of tumor cell nests that were lined by flattened endothelium with no supporting smooth muscle or elastica, and/or were filled with lymphatic fluid. Tumor cell nests in spaces that were either not lined by endothelial cells or were lined by endothelial-like cells, probably tumor-stromal fibroblasts, were classified as stroma-invasive tumor cell nests. Similarly, we defined BVI in H\&E-stained sections, as tumor cell nests in spaces and around the clump of tumor cell nests that were lined by endothelium, that is, not flattened, and/or were filled with red blood cells [16]. The whole section was examined. In order to score lymphatic invasion, only peritumoral areas, and peritumoral lymphatic invasion were counted as lymphatic invasion. Intratumoral lymphatic invasion was not counted in this study. In most cases, intratumoral lymphatic invasion can be misinterpreted as retraction artifact and it was not the purpose of our study to evaluate artifacts.

For this analysis, we evaluated LVI in adjacent stromal tissue (peritumoral area) with a $\times 200$ magnification, with sequential assessment by two investigators, as recommended by the First International Consensus on the Methodology of Lymphangiogenesis Quantification in Solid Human Tumors [27]. We have not used double immunostaining for D2-40 and Ki67 monoclonal antibody for the purpose of counting the number of proliferating lymphatic endothelial cells [27]. Vessels were considered as lymphatic when the endothelium stained with both D2-40 and CD31 antibodies. Vessels were classified as blood vessels when the endothelium stained only for the CD31 monoclonal antibody and was negative for D2-40 in consecutive sections. Vessels that were D2-40 and CD31 positive and had red blood cells in the lumen were considered lymphatic vessels. The red blood cells could be present in lymphatic-blood vessel capillary shunting or bleeding into lymphatic vessels. Also, vessels that were D2-40 positive but were negative for CD31 antibody were considered lymphatic vessels (Figure 1).

Estrogen (ER) and progesterone (PR) receptor expression were determined by a method for scoring immunostaining signal, according to Allred et al $[28,29]$. A proportion score (PS) is assigned representing the estimated proportion of tumor cells staining considering all positive cells (range 0-5). Score 0 refers to no cells having been stained; score $1,1 \%$ of tumor cells stained; score $2,10 \%$ of cells stained; score 3, 1/3 of cells stained; score 4, 2/3 of cells stained; and score 5, 100\% of cells stained. An intensity score (IS) is assigned representing the estimated average staining intensity of positive tumor cells (range 0-3). A total score (TS) is calculated from the sum of PS and IS (ranging from 0, 2-8) [28]. A positive result for both ER and PR is defined as TS $\geq 3$, which was validated in clinical studies $[28,29]$. Ki67 was evaluated by the percentage of neoplastic cells showing nuclear staining in the most proliferative area ("hot spot"). Tumors were grouped in four categories: $<10 \%, 10-25 \%, 25-50 \%$ and $>50 \%$ [30]. Cases were classified as p53 positive when more than $10 \%$ of neoplastic cells exhibited positive nuclear staining [25]. The Her2/neu stained sections were classified according to Dako-HercepTest ${ }^{\mathrm{TM}}$ scoring system [31]. E-cadherin (Ecad) reactivity was analyzed using a semiquantitative scoring system and only the citoplasmic membrane staining was considered. The reactivity was graded as " 0 " if there was no evidence of staining, " $1+"$ if $1-25 \%$ of cells stained, "2+" if 26-49\% stained, " $3+$ " if $50-74 \%$ stained, and " $4+$ " if $>75 \%$ of cells stained [32].

Statistical analysis was performed using the Epi-info $6.04 \mathrm{~b}$, SPSS 8.0 and WinStat software. We calculated McNemars sign test and Cohen's Kappa for concordance regarding vessel invasion evaluated with different methods and the correlation coefficients between variables according to Pearson or Spearman. Comparisons among the three groups were done by one-way analysis of variance (ANOVA) or Kruskall-Wallis test. The relationship 


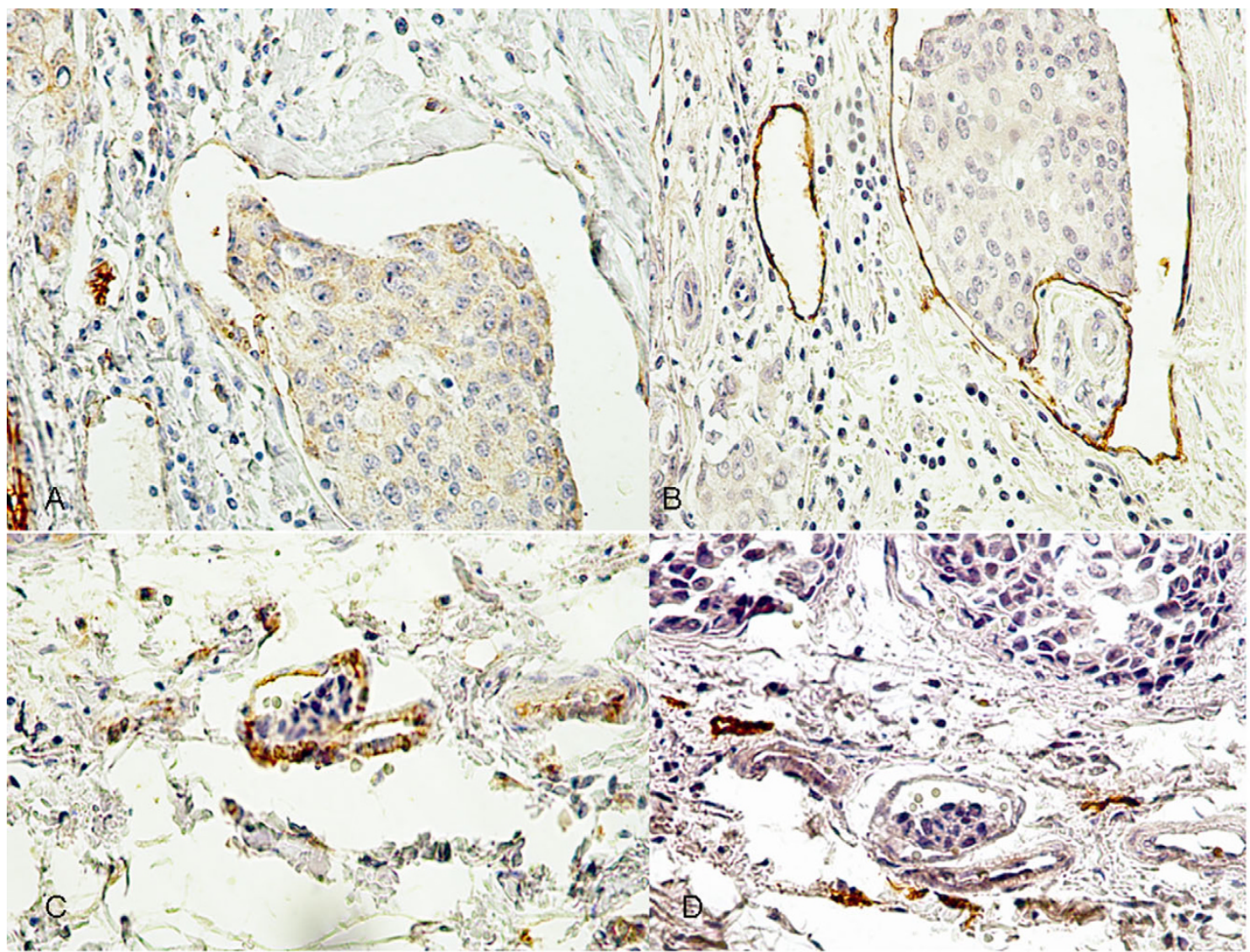

\section{Figure I}

Lymphatic and blood vessels in sections of invasive breast cancer stained for D2-40 and CD3 I. Lymphatic vessel invasion stained for CD3 I (A) and D2-40 (B) in sections of breast tumors from the same case. In A, CD3 I positive endothelium and in B, D2-40 positive endothelium ( $\times 400)$. Blood vessel invasion stained for CD3I (C) and D2-40 (D) in sections of breast tumors from the same case. In C, CD3 I positive endothelium and in D, D2-40 negative endothelium ( $\times 400)$. In $B$ and $C$, the endothelium of lymphatic vessels without invasion was also immunostained.

between LVI and BVI and tumor characteristics was evaluated with the help of a logistic regression analysis [33,34].

\section{Results}

The age of patients ranged from 27 to 88 years $($ mean $=$ 55.9 years, median $=52$ years). Clinicopathologic features of the tumors are summarized in Table 2.

Immunohistochemical features according to axillary lymph node status are summarized in Table 3.

LVI and BVI were found more frequently in the immunostained sections than the H\&E-stained sections (Table 4; Figure 2). We detected LVI in 38/123 cases (30.9\%) and BVI in $21 / 123$ cases $(17.1 \%)$, when adding the two detection methods. In 11/123 cases we detected BVI and LVI in the same case. In 10/123 cases we detected only BVI and in 27/123 cases only LVI. Cohen's Kappa for the diagnos- tic agreement between both methods was moderate for lymphatic vessel invasion $($ Kappa $=0.433)$ and poor for blood vessel invasion (Kappa $=0.198)($ Table 4$)$. Table 4 includes three cases of LVI detected in H\&E-stained slides that were not found in IHC sections. The foci of LVI in these cases were extremely small and a single focus was present in each case. These extremely small foci were not present on the deeper sections used for IHC. The same situation occurred in two cases of BVI (Table 4). In our cases, we did not detect emboli in sections that were D2-40 positive and consecutively CD31 negative. All cases that showed red blood cells inside the lumen and tumor emboli, were D2-40 negative and CD31 positive, and these vessels were considered blood vessels.

Results of the LVI and BVI assessed by H\&E and immunohistochemistry are summarized in Table 5. 
Table 2: Clinicopathologic features of I 23 cases of invasive mammary carcinomas according to axillary lymph node status

\begin{tabular}{|c|c|c|c|c|}
\hline Characteristics & Mac-Met n (\%) & Mic-Met n (\%) & LNN n (\%) & Total n (\%) \\
\hline \multicolumn{5}{|l|}{ Age } \\
\hline$\leq 52$ years & $22(53.7)$ & $21(51.2)$ & $20(48.8)$ & $63(51.2)$ \\
\hline$>52$ years & $19(46.3)$ & $20(49.8)$ & $21(51.2)$ & $60(49.8)$ \\
\hline \multicolumn{5}{|c|}{ Menopausal status } \\
\hline Premenopausal & $20(48.8)$ & $18(43.9)$ & $20(48.8)$ & $58(47.2)$ \\
\hline Postmenopausal & $21(51.2)$ & $23(56.1)$ & $21(51.2)$ & $65(52.8)$ \\
\hline \multicolumn{5}{|c|}{ Tumor Size (TNM) } \\
\hline TI & $10(24.4)$ & $17(4 \mid .5)$ & $17(4 \mid .5)$ & $44(35.8)$ \\
\hline T2 & $24(58.5)$ & $23(56.1)$ & $18(43.9)$ & $65(52.8)$ \\
\hline $\mathrm{T} 3$ & $7(17.1)$ & I (2.4) & $6(14.6)$ & $14(11.4)$ \\
\hline \multicolumn{5}{|l|}{ Histologic type } \\
\hline Ductal NST & $36(87.8)$ & $33(80.4)$ & $36(87.8)$ & $105(85.4)$ \\
\hline Lobular & $3(7.4)$ & $5(12.2)$ & $2(4.8)$ & $10(8.1)$ \\
\hline Other type & $2(4.8)$ & $3(7.4)$ & $3(7.4)$ & $8(6.5)$ \\
\hline \multicolumn{5}{|l|}{ Histologic grade* } \\
\hline Grade I & $9(22)$ & $14(34.1)$ & $13(31.7)$ & $36(29.3)$ \\
\hline Grade II & $21(5 \mid .2)$ & $18(43.9)$ & $19(46.3)$ & $58(47.2)$ \\
\hline Grade III & $11(26.8)$ & $9(22)$ & $9(22)$ & $29(23.6)$ \\
\hline Total & $41(100)$ & $41(100)$ & $41(100)$ & $123(100)$ \\
\hline
\end{tabular}

Mac-Met = macrometastases; Mic-Met = micrometastases; $\mathrm{LNN}=$ lymph node negative; $\mathrm{n}=$ number of cases; NST = non-special type

*Tumors with lymphatic invasion showed a higher histologic grade $(\mathrm{p}=0.013)$. This correlation with lymphatic invasion was significant in $\mathrm{H} \& \mathrm{E}-$ sections and also in IHC-sections.

LVI was positively related to the presence of metastases ( $\mathrm{p}$ $=0.002$ ) (Table 5), and was more frequently found in the subgroup with macrometastases (12/17 cases). No relationship was observed between BVI and the presence of metastases $(\mathrm{p}=0.81)$.

Tumors with LVI showed higher histologic grade $(\mathrm{p}=$ $0.013)$, an increased Ki67 score ( $\mathrm{p}=0.00013)$, and high mitotic score $(\mathrm{p}=0.0002)$, but lower estrogen $(\mathrm{p}=$ $0.0016)$ and lower progesterone $(\mathrm{p}=0.00017)$ receptor scores. The other variables (p53, Her2/neu and E-cadherin) did not show any relation to LVI and/or BVI and lymph node status (Tables 2 and 3 ).

Since several of these variables are correlated, we used a logistic regression analysis with the lymphatic invasion as the dependent variable and the aforementioned variables as the independent ones, including the histologic grade. The following variables entered the final regression model, which classified $82.93 \%$ of the cases correctly: progesterone score $(\mathrm{B}=-0.3295 ; \mathrm{p}=0.0283)$ and Ki67 score (B $=0.7184 ; p=0.0055)$. In contrast, we could not find a significant logistic regression model for BVI regarding the aforementioned variables.

No relationship was observed between age of patients, histologic tumor type and LVI or BVI ( $>0.05)$. BVI was positively related to tumor size $(\mathrm{p}=0.009)$, and was more frequent in tumors greater than $2 \mathrm{~cm}$. No relationship was observed between LVI and tumor size.
In addition to lymphatic vessel endothelium, the D2-40 antibody also stained myoepithelial cells of normal ducts and lobules in the breast parenchyma adjacent to the tumor in all 123 cases.

\section{Discussion}

Our study confirmed that D2-40 stains the endothelium of lymphatic vessels and is useful and reliable in detecting LVI in invasive mammary carcinomas. In our study, LVI was related to breast cancers with high aggressive features (high Ki67 score, high histologic grade, negative hormone receptors expression). We found an inverse correlation between ER and PR expression and LVI. Similar to our study, other authors found a correlation between high histologic grade and Ki67 score to LVI, and a significantly increased risk for tumor recurrence or deaths regardless of axillary node status $[3,16,35]$. Instead of being explained by stroma retraction artifacts, as proposed by Acs et al [36], these correlations could be explained by the biologic properties of the tumor. Tumors with LVI are less differentiated, fast-growing and high grade tumors that offer greater clonal variety of tumor cells. Therefore, there is greater chance of cells capable of invading lymphatic vessels compared with low-grade, slow-growing tumors [3]. The pathophysiology of tumor related blood vessels is completely different. Capillaries are feeder vessels that ensure tissue viability, and promote tumor growth and nutrition in malignant tumors. Lymphatic vessels, on the other hand, are draining vessels that are not essential for tumor metabolism and therefore would not provide any 
Table 3: Immunohistochemical features of I 23 cases of invasive mammary carcinomas according to axillary lymph node status

\begin{tabular}{|c|c|c|c|c|}
\hline IHC features & Mac-Met n (\%) & Mic-Met n (\%) & LNN n (\%) & Total n (\%) \\
\hline \multicolumn{5}{|l|}{ ER * } \\
\hline Positive & 31 (75.6) & $35(85.4)$ & 34 (82.9) & $100(81.3)$ \\
\hline Negative & $10(24.4)$ & $6(14.6)$ & $7(17.1)$ & $23(18.7)$ \\
\hline \multicolumn{5}{|l|}{$\mathbf{P R} *$} \\
\hline Positive & $25(61)$ & 29 (70.7) & $28(68.3)$ & $82(66.7)$ \\
\hline Negative & $16(39)$ & $12(29.3)$ & 13 (3|.7) & $4 I(33.3)$ \\
\hline \multicolumn{5}{|c|}{ Her2/neu score } \\
\hline 0 and $\mathrm{I}+$ & $35(85.4)$ & $32(78)$ & $36(87.8)$ & $103(83.7)$ \\
\hline $2+$ & I (2.4) & I (2.4) & I (2.4) & $3(2.4)$ \\
\hline $3+$ & $5(12.2)$ & $8(19.5)$ & $4(9.8)$ & $17(13.8)$ \\
\hline \multicolumn{5}{|l|}{ P53 } \\
\hline Positive & $17(4 \mid .5)$ & II (26.8) & $10(24.4)$ & $38(30.9)$ \\
\hline Negative & $24(58.5)$ & $30(73.2)$ & $31(75.6)$ & $85(69.1)$ \\
\hline \multicolumn{5}{|l|}{ Ki67 score* } \\
\hline$<10 \%$ & $16(39)$ & $23(56.1)$ & $16(39)$ & $55(44.7)$ \\
\hline $10-25 \%$ & II (26.8) & $9(22)$ & $13(3 \mid .7)$ & $33(26.8)$ \\
\hline $25-50 \%$ & $10(24.4)$ & $6(14.6)$ & $8(19.5)$ & $24(19.5)$ \\
\hline$>50 \%$ & $4(9.8)$ & $3(7.3)$ & $4(9.8)$ & $11(8.9)$ \\
\hline \multicolumn{5}{|c|}{ E-cadherin score } \\
\hline 0 (negative) & $2(4.9)$ & I (2.4) & $2(4.9)$ & $5(4.1)$ \\
\hline $1+$ & $3(7.3)$ & $3(7.3)$ & $2(4.9)$ & $8(6.5)$ \\
\hline $2+$ & $0(0)$ & $2(4.9)$ & I (2.4) & $3(2.4)$ \\
\hline $3+$ & $8(19.5)$ & $6(14.6)$ & $4(9.8)$ & $18(14.6)$ \\
\hline $4+$ & $28(68.3)$ & $29(70.7)$ & $32(78)$ & 89 (72.4) \\
\hline Total & $4 I(100)$ & $41(100)$ & $41(100)$ & $123(100)$ \\
\hline
\end{tabular}

Mac-Met = macrometastases; Mic-Met = micrometastases; $L N N=$ lymph node negative; $n=$ number of cases; IHC = immunohistochemical; ER = estrogen receptor; $\mathrm{PR}=$ progesterone receptor

$*$ Tumors with lymphatic invasion showed an increased Ki67 score $(p=0.00013)$, but lower estrogen $(p=0.0016)$ and progesterone $(p=0.00017)$ receptor scores. This correlation with lymphatic invasion was significant in H\&E-sections and also in IHC-sections.

The other variables showed no statistical significant correlations with LVI identified either by H\&E or IHC-sections.

advantage for tumor growth or survival [3,15]. Tumor vasculature has a markedly different phenotype from normal vessels, and it is highly likely that tumor lymphatic vessels also differ significantly from normal. Gene array studies

Table 4: Lymphatic and blood vessel invasion detected on H\&E and immunostained sections of 123 invasive mammary carcinomas

\begin{tabular}{llll}
\hline H\&E & \multicolumn{3}{c}{ Immunohistochemistry } \\
\cline { 2 - 4 } & Positive n (\%) & Negative n (\%) & Total n (\%) \\
\hline LVI & & & $17(13.8)$ \\
Positive & $14(11.4)$ & $3(2.4)$ & $106(86.2)$ \\
Negative & $21(17.1)$ & $85(69.1)$ & $123(100)$ \\
Total & $35(28.5)$ & $88(71.5)$ & $5(4.1)$ \\
BVI & & $2(1.7)$ & $118(95.9)$ \\
Positive & $3(2.4)$ & $102(82.9)$ & $123(100)$ \\
Negative & $16(13.0)$ & $104(84.6)$ & \\
Total & $19(15.4)$ & & \\
\hline
\end{tabular}

$L V I=$ lymphatic vessel invasion; $B V I=$ blood vessel invasion; $H \& E=$ hematoxylin and eosin; $\mathrm{n}=$ number of cases

Kappa value for $L V I=0.433$ ( $95 \%$ confidence interval: 0.229 to 0.636$)$

Kappa value for $\mathrm{BVI}=0.198$ (95\% confidence interval: -0.144 to $0.54 \mathrm{I})$ on lymphatic endothelium isolated from tumors will therefore be of major interest to help develop new markers relevant to tumor therapy and outcome [27].

E-cadherin, an integral part of adherens junction, maintains the integrity of epithelial cells by facilitating cell-cell adhesion [32]. Decreased expression of E-cadherin in invasive ductal carcinomas has been correlated with higher histologic tumor grade $[37,38]$. We found no relationship between E-cad expression and LVI and BVI, as well as histologic grade and type and other immunohistochemical features of the primary tumor (ER, PR, Ki67, p53, and Her2/neu expressions), confirming results of other studies [39].

To our knowledge, this is the first study that has assessed LVI in breast cancer evaluating cases stratified in subgroups according to axillary lymph node status. LVI was positively related to status of axillary lymph node. LVI detected by both H\&E and IHC was superior in the subgroup with macrometastases (39\% by IHC and $29.3 \%$ by H\&E), compared with the other subgroups. Our results show that LVI detected by D2-40 staining can more relia- 


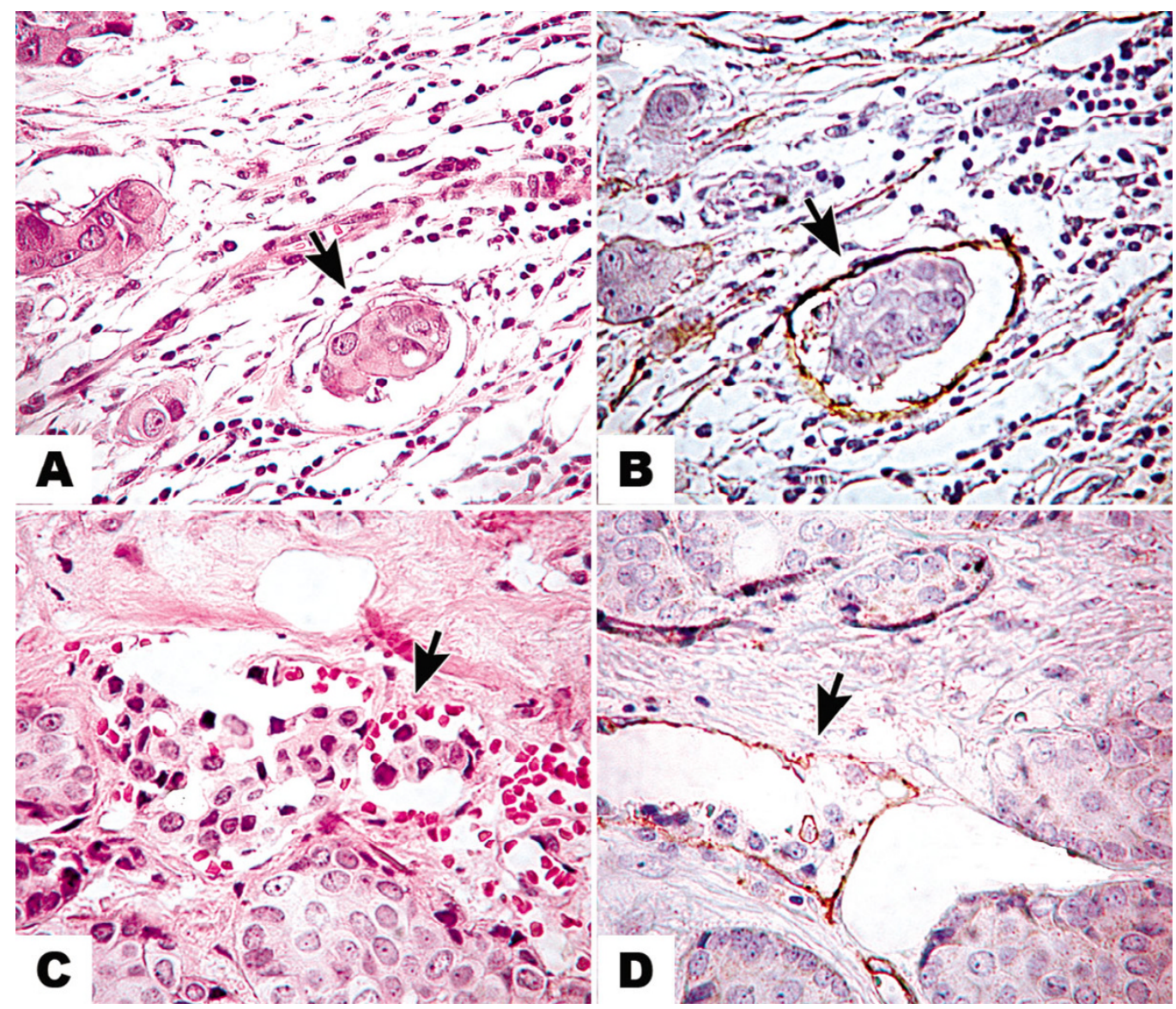

Figure 2

Lymphatic and blood vascular invasion in invasive breast cancer in H\&E and immunostained slides. Lymphatic vascular invasion (arrow) seen in H\&E (A) and D2-40 (B) stained sections of breast tumors from the same case; $\times 400 ; B$ lood vessel invasion (arrow) seen in H\&E (C) and CD3I (D) stained sections; $\times 400$.

bly predict lymph node metastases than the H\&E-stained sections, and could be a reliable tool in predicting poor prognosis, mainly in patients with macrometastases [36].

Our results demonstrated that lymphatic and blood neoplastic emboli were found more frequently in the immunostained sections than in the H\&E-stained sections. The D2-40 is superior to $\mathrm{H} \& \mathrm{E}$ in identifying LVI in invasive mammary carcinomas and can be used in addition to $\mathrm{H} \& \mathrm{E}$ in the assessment of LVI with increased accuracy $[5,20,36,40]$. The Kappa score obtained in our study showed only moderate agreement regarding the LVI, when comparing the $\mathrm{H} \& \mathrm{E}$ and immunohistochemical methods. The increased accuracy of LVI detection using IHC was previously demonstrated in breast cancer

Table 5: Lymphatic and blood vessel invasion in I 23 invasive mammary carcinomas stratified according to nodal status

\begin{tabular}{lllll}
\hline & Mac-Met n (\%) & Mic-Met n (\%) & LNN n (\%) & Total n (\%) \\
\hline LVI (H\&E) * & $12(29.3)$ & $3(7.3)$ & $2(4.9)$ & $17(13.8)$ \\
LVI (IHC) & $16(39)$ & $10(24.4)$ & $9(22)$ & $35(28.5)$ \\
BVI (H\&E) & $2(4.9)$ & $1(2.4)$ & $2(4.9)$ & $5(4.1)$ \\
BVI (IHC) & $6(14.6)$ & $11(26.8)$ & $2(4.9)$ & $19(15.4)$
\end{tabular}

Mac-Met = macrometastases; Mic-Met $=$ micrometastases LNN = lymph node negative $[\mathrm{LVI}=$ lymphatic vessel invasion; $B \mathrm{BV}=$ blood vessel invasion; $\mathrm{n}=$ number of cases; $\mathrm{H} \& \mathrm{E}=$ hematoxylin and eosin; $\mathrm{IHC}=$ immunohistochemistry

$* \mathrm{p}$ value $=0.002$. The other $\mathrm{p}$ values were not statistically significant. 
$[3,5,13,16,20]$ and in other tumors, such as melanoma [41] and gastric cancer [4].

It has long been suggested that LVI, as a diagnostic reproducible feature, should be considered outside the tumor margin $[3,13]$. Yamauchi et al examined intratumoral, peritumoral and tumor emboli distant from tumoral areas, and despite the localization of the emboli they recommend a combination of $\mathrm{H} \& \mathrm{E}$ and D2-40 staining if pathologists find tumor nests suspicious of being emboli in H\&E [16]. Peritumoral vascular invasion, especially lymph vascular invasion, has been included as an adverse prognostic factor in the guidelines and recommendations for postoperative adjuvant systemic therapies of early breast cancer by the International Consensus Panel during St Gallen Conference, 2005 [42]. The presence of peritumoral vascular invasion defined an intermediate risk for patients with node-negative breast disease, but its value in patients with node-positive breast disease was considered uncertain and insufficient at that time [27].

Our results are in agreement with a previous study that compared D2-40 and podoplanin on paraffin sections of a series of head and neck squamous cell carcinomas. Both antibodies were shown to have extremely high specificity (99.7\% and $98.8 \%$ for podoplanin and D2-40) and sensitivity (92.6\% and $97.3 \%$ for podoplanin and D2-40) for lymphatic endothelium [19]. A comparison of different endothelial lymphatic markers showed that the sensitivity of D2-40 to recognize intratumoral lymphatic vessels on serial sections of breast carcinomas is higher than that of LYVE-1, podoplanin or Prox-1 [20].

In our series, the D2-40 also stained myoepithelial cells of normal ducts and lobules of the adjacent peritumoral parenchyma. Although the antibody selectively stained the lymphatic vessel endothelium and was negative in blood vessel endothelium, it is not a specific lymphatic marker. Besides myoepithelial cells of human breast [15], it has been observed that D2-40 also stains basal epithelial cell layers of the epidermis [41] and prostate gland [43].

\section{Conclusion}

Our results show that D2-40 is a useful tool for identification of LVI in breast carcinomas. LVI is related to tumors with higher aggressive features reflecting a potential for lymphatic metastatic spread and possible poor prognosis.

\section{Competing interests}

The author(s) declare that they have no competing interests.

\section{Authors' contributions}

VFZM carried out all immunostains, analyzed all H\&E and IHC stained slides, analyzed lymphatic and blood vessel invasion and wrote the manuscript.

KM carried out the statistical analysis and critically reviewed the manuscript.

FSFS helped the case selection, data collecting and helped the Epi-Info analysis.

GFSR provided technical assistance and performed sections for immunostains and H\&E.

HG has been involved in the study design, drafting and reviewing the manuscript critically.

All authors read and approved the final manuscript.

\section{Acknowledgements}

Supported by grants from Fundação de Amparo à Pesquisa do Estado de Minas Gerais (FAPEMIG) and Conselho Nacional de Desenvolvimento Científico e Tecnológico (CNPq).

We are grateful to Sandra J. Olson, MS, for reviewing the English manuscript.

\section{References}

I. Schoppmann SF, Bayer G, Aumayr K, Taucher S, Geleff S, Rudas M, Kubista E, Hausmaninger H, Samonigg H, Gnant M, Jakesz R, Horvat R, Austrian Breast and Colorectal Cancer Study Group: Prognostic value of lymphangiogenesis and lymphovascular invasion in invasive breast cancer. Ann Surg 2004, 240:306-312.

2. Aoki Y, Tosato G: Lymphatic regeneration: new insights from VEGFR-3 blockade. J Natl Cancer Inst 2005, 97:2-3.

3. Vleugel MM, Bos R, van der Groep P, Greijer AE, Shvarts A, Stel HV, van der Wall E, van Diest PJ: Lack of lymphangiogenesis during breast carcinogenesis. J Clin Pathol 2004, 57:746-75I.

4. Yonemura Y, Endou Y, Tabachi K, Kawamura T, Yun HY, Kameya T, Hayashi I, Bandou E, Sasaki T, Miura M: Evaluation of lymphatic invasion in primary gastric cancer by a new monoclonal antibody, D2-40. Hum Pathol 2006, 37: I 193-II 99.

5. Arnaout-Alkarain A, Kahn HJ, Narod SA, Sun PA, Marks AN: Significance of lymph vessel invasion identified by the endothelial lymphatic marker D2-40 in node negative breast cancer. Mod Pathol 2007, 20:183-191.

6. Choi WW, Lewis MM, Lawson D, Yin-Goen Q, Birdsong GG, Cotsonis GA, Cohen $C$, Young AN: Angiogenic and lymphangiogenic microvessel density in breast carcinoma: correlation with clinicopathologic parameters and VEGF-family gene expression. Mod Pathol 2005, 18: I 43-152.

7. Cunnick GH, Jiang WG, Gomez KF, Mansel RE: Lymphangiogenesis and breast cancer metastasis. Histol Histopathol 2002, 17:863-870.

8. Franchi A, Gallo O, Massi D, Baroni G, Santucci M: Tumor lymphangiogenesis in head and neck squamous cell carcinoma: a morphometric study with clinical correlations. Cancer 2004, 101:973-978.

9. Cursiefen C, Schlotzer-Schrehardt U, Kuchle M, Sorokin L, Breiteneder-Geleff S, Alitalo K, Jackson D: Lymphatic vessels in vascularized human corneas: immunohistochemical investigation using LYVE-I and podoplanin. Invest Ophthalmol Vis Sci 2002, 43:2127-2। 35 .

10. Ebata N, Nodasaka Y, Sawa Y, Yamaoka Y, Makino S, Totsuka $Y$, Yoshida S: Desmoplakin as a specific marker of lymphatic vessels. Microvasc Res 2001, 61:40-48. 
II. Jussila L, Alitalo K: Vascular growth factors and lymphangiogenesis. Physiol Rev 2002, 82:673-700.

12. Wigle JT, Oliver G: Prox I function is required for the development of the murine lymphatic system. Cell 1999, 98:769-778.

13. Kahn HJ, Marks A: A new monoclonal antibody, D2-40, for detection of lymphatic invasion in primary tumors. Lab Invest 2002, 82: | 255- 1257

14. Kahn HJ, Bailey D, Marks A: Monoclonal antibody D2-40, a new marker of lymphatic endothelium, reacts with Kaposi's sarcoma and a subset of angiosarcomas. Mod Pathol 2002, 1 5:434-440.

15. Agarwal B, Saxena R, Morimiya A, Mehrotra S, Badve S: Lymphangiogenesis does not occur in breast cancer. Am J Surg Pathol 2005, 29: | 449-1455.

16. Yamauchi C, Hasebe T, Iwasaki M, Imoto S, Wada N, Fukayama M Ochiai A: Accurate assessment of lymph vessel tumor emboli in invasive ductal carcinoma of the breast according to tumor areas, and their prognostic significance. Hum Pathol 2007, 38:247-259.

17. Schacht V, Dadras SS, Johnson LA, Jackson DG, Hong YK, Detmar M: Up-regulation of the lymphatic marker podoplanin, a mucintype transmembrane glycoprotein, in human squamous cell carcinomas and germ cell tumors. Am J Pathol 2005, 166:913-921.

18. Van den Eynden GG, Van der Auwera I, Van Laere SJ, Colpaert CG, van Dam P, Dirix LY, Vermeulen PB, Van Marck EA: Distinguishing blood and lymph vessel invasion in breast cancer: a prospective immunohistochemical study. $\mathrm{Br}$ J Cancer 2006 , 94(I I): I643-1649.

19. Evangelou E, Kyzas PA, Trikalinos TA: Comparison of the diagnostic accuracy of lymphatic endothelial markers: Bayesian approach. Mod Pathol 2005, I 8: | 490-। 497.

20. Van der Auwera I, Van den Eynden GG, Colpaert CG, Van Laere SJ, van Dam P, Van Marck EA, Dirix LY, Vermeulen PB: Tumor lymphangiogenesis in inflammatory breast carcinoma: a histomorphometric study. Clin Cancer Res 2005, I I:7637-7642.

2I. Nisato RE, Tille JC, Pepper MS: Lymphangiogenesis and tumor metastasis. Thromb Haemost 2003, 90:591-597.

22. Fukunaga M: Expression of D2-40 in lymphatic endothelium of normal tissues and in vascular tumours. Histopathology 2005, 46:396-402.

23. Greene FL, Page DL, Fleming ID, Fritz AG, Balch CM, Haller DG Morrow M: Breast. In AJCC Cancer Staging Manual 6th edition. Edited by: Greene FL, Page DL, Fleming ID, Fritz AG, Balch CM, Haller DG, Morrow M. New York: Springer; 2002:223-240.

24. Page DL, Jensen RA, Simpson JF: Routinely available indicators of prognosis in breast cancer. Breast Cancer Res Treat 1998, 5 I:195-208.

25. Fitzgibbons PL, Page DL, Weaver D, Thor AD, Allred DC, Clark GM, Ruby SG, O'Malley F, Simpson JF, Connolly JL, Hayes DF, Edge SB, Lichter A, Schnitt S): Prognostic factors in breast cancer. College of American Pathologists Consensus Statement 1999. Arch Pathol Lab Med 2000, I 24:966-978.

26. Elston CW, Ellis IO: Pathological prognostic factors in breast cancer. I. The value of histological grade in breast cancer: experience from a large study with long-term follow-up. Histopathology 1991, 19:403-410.

27. Van der Auwera I, Cao Y, Tille JC, Pepper MS, Jackson DG, Fox SB, Harris AL, Dirix LY, Vermeulen PB: First international consensus on the methodology of lymphangiogenesis quantification in solid human tumours. Br J Cancer 2006, 95: I6II-1625.

28. Allred DC, Harvey JM, Berardo M, Clark GM: Prognostic and predictive factors in breast cancer by immunohistochemical analysis. Mod Pathol 1998, I I:I55-168.

29. Harvey JM, Clark GM, Osborne CK, Allews DC: Estrogen receptor status by immunohistochemistry is superior to the ligandbinding assay for predicting response to adjuvant endocrine therapy in breast cancer. J Clin Oncol 1999, 17:1474-1481.

30. Keshgegian AA, Cnaan A: Proliferation markers in breast carcinoma. Mitotic figure count, S-Phase fraction, proliferating cell nuclear antigen, Ki-67 and MIB-I. Am J Clin Pathol 1995, 104:42-49.

31. Dako Herceptest ${ }^{\mathrm{TM}}$ : A manual for interpretation. 1999

32. Gupta A, Deshpande CG, Badve S: Role of E-Cadherins in development of lymphatic tumor emboli. Cancer 2003, 97:234I-2347.
33. Lorand-Metze I, Meira DG, Lima CS, Vassallo J, Metze K: The differential diagnosis between aplastic anemia and hypocellular myelodysplasia in patients with pancytopenia. Haematologica 1999, 84:564-565.

34. Delamain MT, Metze K, Marques JF, Reis AR, De Souza CA, LorandMetze I: Optimization of CD34+ collection for autologous transplantation using the evolution of peripheral blood cell counts after mobilization with chemotherapy and G-CSF. Transfus Apher Sci 2006, 34:33-40.

35. Tezuka K, Onoda N, Takashima T, Takagaki K, Ishikawa T, Wakasa T, Wakasa K, Hirakawa K: Prognostic significance of lymphovascular invasion diagnosed by lymphatic endothelium immunostaining in breast cancer patients. Oncol Rep 2007, 17:997-1003.

36. Acs G, Dumoff KL, Solin LJ, Pasha T, Xu X, Zhang PJ: Extensive retraction artifact correlates with lymphatic invasion and nodal metastasis and predicts poor outcome in early stage breast carcinoma. Am J Surg Pathol 2007, 3 I:129-140.

37. Siitonen SM, Kononen JT, Helin HJ, Rantala IS, Holli KA, Isola J]: Reduced E-cadherin expression is associated with invasiveness and unfavorable prognosis in breast cancer. $\mathrm{Am} / \mathrm{Clin}$ Pathol 1996, 105:394-402.

38. Charpin C, Garcia S, Bouvier C, Devictor B, Andrac L, Choux R, Lavaut $M$ : E-cadherin quantitative immunocytochemical assays in breast carcinomas. J Pathol 1997, 181:294-300.

39. Qureshi HS, Linden MD, Divine G, Raju UB: E-cadherin status in breast cancer correlates with histologic type but does not correlate with established prognostic parameters. Am J Clin Pathol 2006, I 25:377-385.

40. Pepper MS: Lymphangiogenesis and tumor metastasis: myth or reality? Clin Cancer Res 200I, 7:462-468.

4I. Niakosari F, Kahn HJ, Marks A, From L: Detection of lymphatic invasion in primary melanoma with monoclonal antibody D2-40: a new selective immunohistochemical marker of lymphatic endothelium. Arch Dermatol 2005, I 4 I:440-444.

42. Goldhirsch A, Glick JH, Gelber RD, Coates AS, Thurlimann B, Senn HJ, Panel members: Meeting highlights: international expert consensus on the primary therapy of early breast cancer 2005. Ann Oncol 2005, 16:1569-1583.

43. Zeng Y, Opeskin K, Horvath LG, Sutherland RL, Williams ED: Lymphatic vessel density and lymph node metastasis in prostate cancer. Prostate 2005, 65:222-230.

\section{Pre-publication history}

The pre-publication history for this paper can be accessed here:

\section{http://www.biomedcentral.com/1471-2407/8/64/prepub}

Publish with Bio Med Central and every scientist can read your work free of charge

"BioMed Central will be the most significant development for disseminating the results of biomedical research in our lifetime. "

Sir Paul Nurse, Cancer Research UK

Your research papers will be:

- available free of charge to the entire biomedical community

- peer reviewed and published immediately upon acceptance

- cited in PubMed and archived on PubMed Central

- yours - you keep the copyright
BioMedcentral 